\title{
立ち乗り式四輪型パーソナルモビリティ・ビークルにおける 人間の立位姿勢での重心移動
}

\author{
中川 智皓*1，森田 悠介*2，新谷 篤彦*1，伊藤 智博*1
}

\section{Standing posture analysis of a human on a four-wheel stand-up-type personal mobility vehicle}

\author{
Chihiro NAKAGAWA ${ }^{* 1}$, Yusuke MORITA*2, \\ Atsuhiko SHINTANI*1 and Tomohiro ITO*1 \\ ${ }^{{ }_{1},{ }^{*} 2}$ Graduate School of Engineering, Osaka Prefecture University \\ 1-1 Gakuen, Naka-ku, Sakai-shi, Osaka 599-8531, Japan
}

\section{Received 17 February 2016}

\begin{abstract}
In recent years, personal mobility vehicles (PMVs) have attracted huge attentions and widely developed. Compact PMVs can move through narrow spaces and they are expected to be used in pedestrian spaces. In this study, we aim to develop a four-wheel stand-up-type personal mobility vehicle for people who cannot walk far distantly because of the pain of foot or waist although they are able to walk for a short distance. The coupled model of human and vehicle is constructed by using multibody dynamics. In the model, the vehicle is expressed by one rigid body. The wheels, body, and handle are considered as a rigid body together. A human is expressed by 8 rigid bodies (foot, lower leg, femoral, body, head, upper arm, lower arm, and hand). The vehicle of the coupled model is accelerated in the numerical simulations. The behaviors of the center of gravity of a human with and without handle constraint are analyzed. As the result of the parametric study, it is found that the center of gravity movement is smaller when the value of the maximum acceleration and the acceleration time are small. It is also found that as the angle of the upper arm becomes large, the movement of the center of gravity is decreased.
\end{abstract}

Key words : Personal mobility vehicle, Numerical simulation, Human model, Four-wheel stand-up-type vehicle, Multibody dynamics

\section{1. 緒言}

近年，パーソナルモビリティ・ビークル（以下 PMV）と呼ばれる個人用の移動車両が注目されている. PMV は，小型で，小回りが利くため，歩行空間における新たな移動手段として期待されている．既に，様々なタイプ の車両が開発されており, Segway（Segway Inc., 2016）やWinglet（トヨタ自動車HP，2016）のような倒立振子 型と呼ばれる立ち乗り式の車両や，UNI-CUB（本田技研工業株式会社 HP，2016）やシニアカーのような着席型 の車両などがある. PMV の中でもとりわけ研究が盛んな倒立振子型車両は, 車両と操縦者の安定性を姿勢安定化 制御により実現している。一方，三輪もしくは四輪型の車両は，車両と操縦者の静的安定性が確保される．本研 究では, 操縦者の静的安定性を確保する点から四輪型, また, 周囲の歩行者と PMV の心理的な親和性（中川他, 2012）を考慮して，より小型で製作可能な立ち乗り式四輪型 PMV の開発を目指す. 歩行が可能ではあるものの, 足の痛みや腰痛の為に徒歩での移動を負担に感じる人をターゲットに含む. 車両上の人間の挙動を詳細に把握す る為, マルチボディダイナミクス（以下 MBD）を用い，車両と人間が連成した解析モデルを構築する. 車両が 加速する際の人間の重心挙動に着目し, 加速条件（加速時間, 最大加速度）と重心挙動の関係性を把握する. ま

\footnotetext{
No.16-00052 [DOI:10.1299/transjsme.16-00052], J-STAGE Advance Publication date : 26 May, 2016

*1 正員, 大阪府立大学大学院工学研究科（T599-8531 大阪府堺市中区学園町 1-1）

*2 正員, 大阪府立大学大学院工学研究科 (現（株）クボタ)

E-mail of corresponding author: chihiro@me.osakafu-u.ac.jp
} 
た，人間が車両の取っ手を持つ姿勢を，上腕部と前腕部の目標角度により分類し，それぞれの姿勢の場合につい ての重心移動距離の違いを把握することで，理想的な乗車姿勢について検討する.

特に, 本研究では, 人間の立位姿勢に対する基本的な運動に着目することで, 立位姿勢を保持できる限界 加速度や取っ手の適度な取り付け範囲を明らかにする. 特に, PMV として日本の歩道（公道）での使用可能 性を想定した時速 $6 \mathrm{~km}$ 以下（道路交通法「原動機を用いる歩行補助車等の基準」）の条件で想定される加速 度に着目し, 解析的に具体的な加速範囲や取っ手の理想的な位置を求めることで PMV の設計指針の一助とす る.

\section{2. 解析モデル}

車両と人間が連成したモデルを，2 次元の MBD で構築する.

\section{$2 \cdot 1$ 車両モデル}

車両は，取っ手を含めて 1 剛体とする.PMV には様々な形態があり，例えば車両のホイールベースや取っ 手の位置，質量に応じ，車両の転倒条件が大きく異なることが考えられる．PMV の形態によって車両およ びその上の人間の運動が大きく変われば，人間の立位姿勢を保持しや寸い条件を探る際，モデリングや条件 設定が煩雑となる. よって，まずは基本的な人間の立位時の運動を見るため, 本研究では車両の転倒は考慮 しない. ここでは，車両の加速に対する人間の動きにフォーカス寸るため，車両の質量を $m_{v e h i c l e}=5000[\mathrm{~kg}]$ と大 きく設定することで人間の動きが車両に与える影響を無視した．車両の移動方向は水平方向に限定し，鉛直方向 及び回転方向は拘束する，車両の慣性モーメントは，運動方程式を導出する便宜上 $J_{\text {vehicle }}$ と定義するが，回転方 向の自由度を与えないため, 拘束追加後の運動方程式では消去される.

\section{$2 \cdot 2$ 人間モデル}

人間モデルは，平均的な日本人男性をモデル化の対象とする．足部・下腿部・大腿部・胴体部・頭部・上腕部・ 前腕部・手部の 8 剛体 $\left(\mathrm{A}_{n}, n=1,2, \cdots, 8\right)$ で構成されており, 図 1 (a) に各部分長, 図 1 (b) に各点の定義 を示す. 各剛体はピンジョイント $\mathrm{P}_{i} \quad(i=1,2, \cdots, 7)$ で拘束されており, それぞれ足首・膝・股関節・首・肩・ 肘・手首を示寸. 各ピンジョイント部には, 直立姿勢を保持する関節の粘弾性を表す回転バネ $k_{i}$ と回転ダンパ $c_{i}$ を設ける．また，直立姿勢を保持するように制御トルク $T_{i}$ が働く．ただし，腕による意識的な操作が無いと仮定 した場合の，取っ手と手部の拘束による人間の重心移動の違いを把握する為，肩，肘，手首の各関節に入力され る制御トルク $T_{5}, T_{6}, T_{7}$ は働かないものとする. 各諸元は先行研究（荒川他, 2012a）の各值と同じとする.
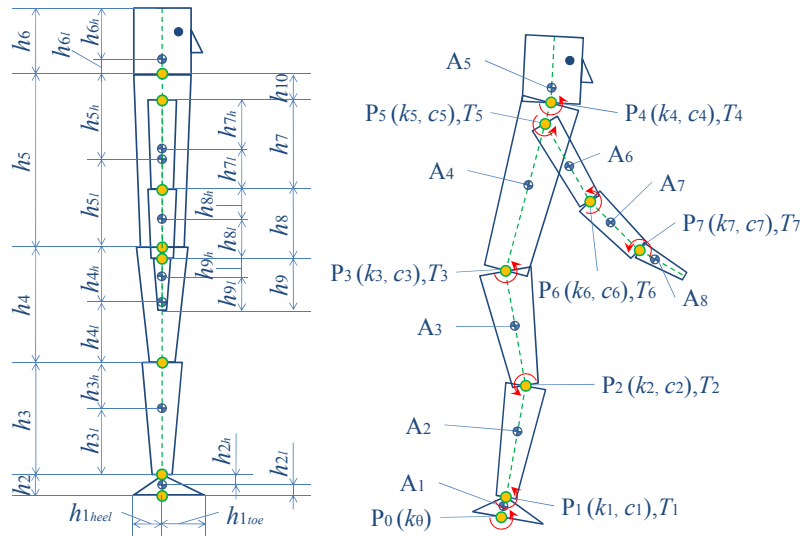

(a) Definition of length (b) Definition of each points

Fig. 1 Human model. Human model consists of eight rigid bodies. The definition of length and the definition of each points are showed in (a) and (b).

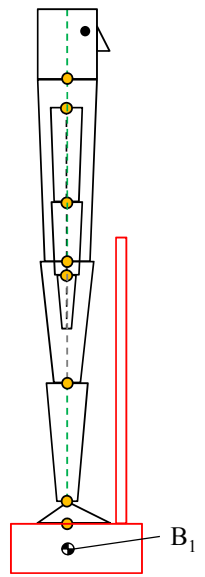

(a) Without constraint

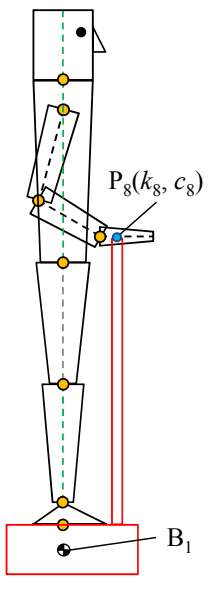

(b) With constraint
Fig. 2 Coupled model of vehicle and driver. (a) shows that the hand and a handle aren't constrained. (b) shows that the hand and a handle are constrained. 


\section{$2 \cdot 3$ 車両と人間の連成モデル}

\section{$2 \cdot 3 \cdot 1$ 取っ手を持たない場合}

取っ手を持たない場合の，車両と人間の連成モデルを図 2 (a) に示寸. 先行研究（荒川他，2012b）と同様に， 車両と人間はピンジョイント $\mathrm{P}_{0} に て ，$ 足裏回転バネ定数 $k_{\theta} \quad\left(=4.5 \times 10^{3}[\mathrm{Nm} / \mathrm{rad}]\right)$ を用いて鉛直方向軸が揃うよ うに拘束する.

\section{$2 \cdot 3 \cdot 2$ 取っ手を持つ場合}

取っ手を持つ場合の, 車両と人間の連成モデルを図 $9(\mathrm{~b})$ に示す. 取っ手と人間の手部との拘束点を $\mathrm{P}_{8}$ とする. ここでの拘束は，バネ・ダンパによる仮想的な拘束力を設けることで実現させる．鉛直方向の粘弾性係数を $k_{8 x}=2.0 \times 10^{4}[\mathrm{Nm} / \mathrm{rad}], \quad c_{8 x}=1.0 \times 10^{3}[\mathrm{Nms} / \mathrm{rad}]$, 水平方向の粘弾性係数を $k_{8 y}=2.0 \times 10^{4}[\mathrm{Nm} / \mathrm{rad}], c_{8 y}=1.0 \times 10^{3}$ $[\mathrm{Nms} / \mathrm{rad}]$ と設定した.

\section{$2 \cdot 4$ 運動方程式}

先行研究（荒川他, 2012b）と同様に，拘束条件追加法（田島, 2006）を用いて運動方程式を導出する. 車両モ デルの水平方向変位を $R_{\mathrm{OB}_{x}}$, 速度を $V_{\mathrm{OB}_{x}}$ とする. また, 人間モデルの 各部位 $\left(\mathrm{A}_{n}\right)$ の回転角度を $\theta_{\mathrm{OA}_{n}}$, 回転 角速度を $\omega_{\mathrm{OA}_{n}}$ とおく．但し，上向き鉛直方向からの回転角とし，反時計回りを正とする. 2 次元の拘束条件追加 法で用いる行列を用意する. 回転行列 $\mathbf{C}_{O A_{n}}$, 回転行列の時間微分の際に用いる行列 $\chi, X, Y$ 方向成分を取り出す 行列 $\mathbf{d}_{\mathrm{X}}, \mathbf{d}_{\mathrm{Y}}$ を次に示す. 田島（2006）における原則的なルールに準じ, 行列およびベクトルには太文字, スカ ラー変数には斜体の細文字を用いている.

$$
\begin{aligned}
& \mathbf{C}_{\mathrm{OA}_{n}}=\left[\begin{array}{cc}
\cos \theta_{\mathrm{OA}_{n}} & -\sin \theta_{\mathrm{OA}_{n}} \\
\sin \theta_{\mathrm{OA}_{n}} & \cos \theta_{\mathrm{OA}_{n}}
\end{array}\right] \\
& \chi=\left[\begin{array}{cc}
0 & -1 \\
1 & 0
\end{array}\right] \\
& \mathbf{d}_{\mathrm{X}}=\left[\begin{array}{l}
1 \\
0
\end{array}\right] \\
& \mathbf{d}_{\mathrm{Y}}=\left[\begin{array}{l}
0 \\
1
\end{array}\right]
\end{aligned}
$$

各剛体における運動方程式を導出寸る. 図 3 に示寸ように, 慣性系から見た各剛体の重心の位置ベクトルを $\mathbf{R}_{\mathrm{q}}$ と表し, 各質点間における位置ベクトルを $\mathbf{r}_{\mathrm{q}}$ と表す. $\mathbf{R}_{\mathrm{q}}$ の時間微分により得られる速度ベクトルを $\mathbf{V}_{\mathrm{q}}$ と表し, 右下添え字中の左から 2 番目の文字の座標系で表される速度ベクトルを $\mathbf{V}_{\mathrm{q}}^{\prime}$ とする. すなわち, $\mathrm{q}=\mathrm{OA}_{1}$ の場合, $\mathrm{A}_{1}$ の座標系で表される速度べクトルを意味する. 拘束追加前の一般化速度ベクトル $\mathbf{H}(27 \times 1$ 行列）と拘束追加 後の一般化速度ベクトル $\mathbf{S}(9 \times 1$ 行列 $)$ は

$$
\begin{aligned}
& \mathbf{H}=\left[\begin{array}{lllllll}
\mathbf{V}_{\mathrm{OA}_{1}}^{\prime} & \omega_{\mathrm{OA}_{1}} & \cdots & \mathbf{V}_{\mathrm{OA}_{n}}^{\prime} & \omega_{\mathrm{OA}_{n}} & \mathbf{V}_{\mathrm{OB}_{1}}^{\prime} & \omega_{\mathrm{OB}_{1}}
\end{array}\right]^{T} \\
& \mathbf{S}=\left[\begin{array}{lllll}
\omega_{\mathrm{OA}_{1}} & \cdots & \omega_{\mathrm{OA}_{n}} & V_{\mathrm{OB}_{x} l_{x}}
\end{array}\right]^{\mathrm{T}}
\end{aligned}
$$

である。 


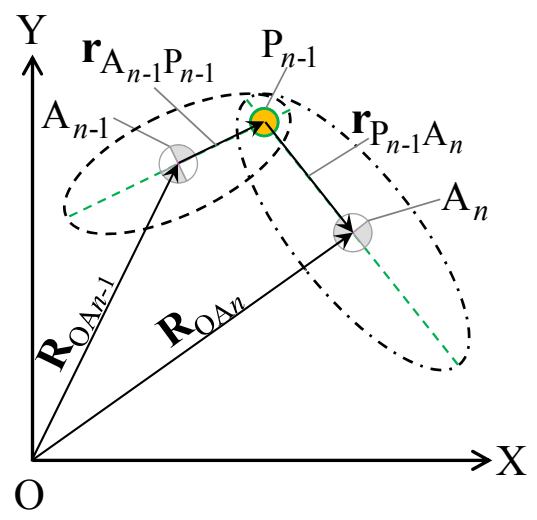

Fig. 3 Explanatory drawing of velocity transformation. This figure shows the relationship among the points and the position vectors of each rigid body.

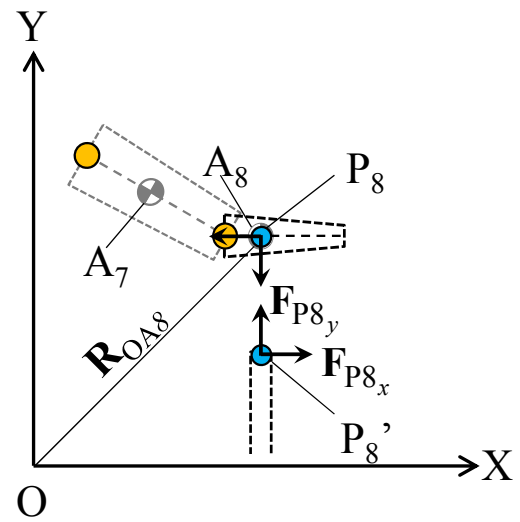

Fig. 4 Constraint of the hand and the handle. Considering the reaction force $\left(F_{P 8_{x}}, F_{P 8_{y}}\right), \mathrm{P}_{8}$ and $\mathrm{P}_{8}^{\prime}$ are constrained.

拘束追加前と追加後の一般化速度ベクトルには, 速度変換行列 $\mathbf{H}_{s}$ を用いて次式が成り立つ.

$$
\mathbf{H}=\mathbf{H}_{\mathrm{S}} \mathbf{S}
$$

故に，車両と人間の連成モデルにおける速度変換行列 $\mathbf{H}_{s}(27 \times 9$ 行列 $)$ は式（8）で表せる.

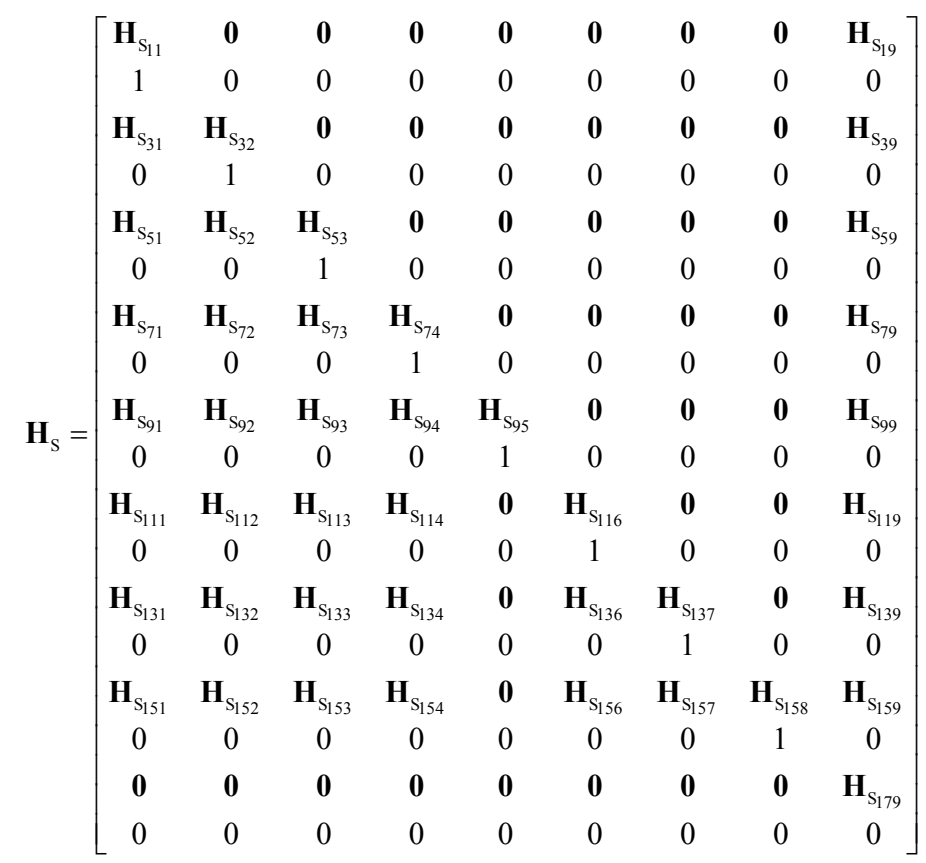

式（8）の $e$ 行 $j$ 列の要素を $\mathbf{H}_{\mathrm{S}_{e j}}$ と表す. $e=2 j-1, j=1,2, \cdots, 5$ の場合, $\mathbf{H}_{\mathrm{S}_{e j}}$ は次に示寸数式で表せる.

$$
\mathbf{H}_{\mathrm{S}_{e j}}=\chi \mathbf{d}_{\mathrm{Y}} \mathbf{r}_{\mathrm{P}_{j-1} \mathrm{~A}_{j}}
$$

$e=2 j-1, j=6,7,8$ の場合, $\mathbf{H}_{\mathrm{s}_{e j}}$ は次に示寸数式で表せる.

$$
\mathbf{H}_{\mathrm{S}_{e j}}=-\chi \mathbf{d}_{\mathrm{Y}} \mathbf{r}_{\mathrm{P}_{j-1} \mathrm{~A}_{j}}
$$


$e=3,5, \cdots, 15, j=1,2,3,4$ の場合, $\mathbf{H}_{s_{e j}}$ は次に示寸数式で表せる.

$$
\mathbf{H}_{\mathrm{S}_{e j}}=\mathbf{C}_{\mathrm{OA}_{(e+1) / 2}}^{-1} \mathbf{C}_{\mathrm{OA}_{j}} \chi \mathbf{d}_{\mathrm{Y}_{\mathrm{P}}} \mathbf{r}_{\mathrm{P}_{-1} \mathrm{P}_{j}}
$$

但し, $e=11,13,15, j=4$ の場合, $\mathbf{H}_{\mathrm{s}_{e j}}$ は次に示寸数式で表せる.

$$
\mathbf{H}_{\mathrm{S}_{e j}}=\mathbf{C}_{\mathrm{OA}(e+1) / 2}^{-1} \mathbf{C}_{\mathrm{OA}_{j}} \boldsymbol{\chi} \mathbf{d}_{\mathrm{Y}} \mathbf{r}_{\mathrm{P}_{j-1} \mathrm{P}_{j+1}}
$$

$e=13,15, j=6,7$ の場合, $\mathbf{H}_{\mathrm{S}_{e j}}$ は次に示す数式で表せる.

$$
\mathbf{H}_{\mathrm{S}_{e j}}=-\mathbf{C}_{\mathrm{OA}(e+1) / 2}^{-1} \mathbf{C}_{\mathrm{OA}_{j}} \boldsymbol{\chi} \mathbf{d}_{\mathrm{Y}} \mathbf{r}_{\mathrm{P}_{j-1} \mathrm{P}_{j}}
$$

$e=1,3, \cdots, 15, j=9$ の場合, $\mathbf{H}_{\mathrm{s}_{e j}}$ は次に示寸数式で表せる.

$$
\mathbf{H}_{\mathrm{S}_{e j}}=\mathbf{C}_{\mathrm{OA}_{(e+1) / 2}}^{-1} \mathbf{d}_{\mathrm{X}}
$$

$e=17, j=9$ の場合, $\mathbf{H}_{\mathrm{S}_{e j}}$ は次に示寸数式で表せる.

$$
\mathbf{H}_{\mathrm{s}_{e j}}=\mathbf{d}_{\mathrm{X}}
$$

連成モデルにおける拘束追加前の質量行列 $\mathbf{m}^{\mathrm{H}} \quad(27 \times 27$ 行列 $)$ は，人間モデルおよび車両モデルにおける 拘束追加前の質量行列 $\mathbf{M}_{u}, \mathbf{M}_{\text {vehicle }}$ を用いて, 次の行列で表される. なお, $\mathbf{m}_{u}(u=n)$ は $n$ 剛体人間モデルの 質量行列， $\mathbf{J}_{u}$ はその慣性行列である.

$$
\begin{aligned}
& \mathbf{M}_{u}=\left[\begin{array}{ccc}
\mathbf{m}_{u} & 0 & 0 \\
0 & \mathbf{m}_{u} & 0 \\
0 & 0 & \mathbf{J}_{u}
\end{array}\right] \\
& \mathbf{M}_{\text {vehicle }}=\left[\begin{array}{ccc}
m_{\text {vehicle }} & 0 & 0 \\
0 & m_{\text {vehicle }} & 0 \\
0 & 0 & J_{\text {vehicle }}
\end{array}\right] \\
& \mathbf{m}^{\mathrm{H}}=\left[\begin{array}{cc}
\mathbf{M}_{u} & \mathbf{0} \\
\mathbf{0} & \mathbf{M}_{\text {vehicle }}
\end{array}\right]
\end{aligned}
$$

拘束追加前における各剛体の回転方向作用力 $f_{3 n}^{\mathrm{H}}, f_{27}^{\mathrm{H}}$ を以下に示す.

$$
\begin{aligned}
& f_{3}^{\mathrm{H}}=k_{1}\left(\theta_{\mathrm{OA}_{2}}-\theta_{\mathrm{OA}_{1}}\right)+c_{1}\left(\omega_{\mathrm{OA}_{2}}-\omega_{\mathrm{OA}_{1}}\right)+k_{\theta}\left(0-\theta_{\mathrm{OA}_{1}}\right)+T_{1} \\
& f_{6}^{\mathrm{H}}=k_{1}\left(\theta_{\mathrm{OA}_{1}}-\theta_{\mathrm{OA}_{2}}\right)+c_{1}\left(\omega_{\mathrm{OA}_{1}}-\omega_{\mathrm{OA}_{2}}\right)+k_{2}\left(\theta_{\mathrm{OA}_{3}}-\theta_{\mathrm{OA}_{2}}\right)+c_{2}\left(\omega_{\mathrm{OA}_{3}}-\omega_{\mathrm{OA}_{2}}\right)-T_{1}+T_{2} \\
& f_{9}^{\mathrm{H}}=k_{2}\left(\theta_{\mathrm{OA}_{2}}-\theta_{\mathrm{OA}_{3}}\right)+c_{2}\left(\omega_{\mathrm{OA}_{2}}-\omega_{\mathrm{OA}_{3}}\right)+k_{3}\left(\theta_{\mathrm{OA}_{4}}-\theta_{\mathrm{OA}_{3}}\right)+c_{3}\left(\omega_{\mathrm{OA}_{4}}-\omega_{\mathrm{OA}_{3}}\right)-T_{2}+T_{3} \\
& f_{12}^{\mathrm{H}}=k_{3}\left(\theta_{\mathrm{OA}_{3}}-\theta_{\mathrm{OA}_{4}}\right)+c_{3}\left(\omega_{\mathrm{OA}_{3}}-\omega_{\mathrm{OA}_{4}}\right)+k_{4}\left(\theta_{\mathrm{OA}_{5}}-\theta_{\mathrm{OA}_{4}}\right)+c_{4}\left(\omega_{\mathrm{OA}_{5}}-\omega_{\mathrm{OA}_{4}}\right) \\
& +k_{5}\left(\theta_{\mathrm{OA}_{6}}-\theta_{\mathrm{OA}_{4}}-\theta_{\mathrm{st}_{6}}\right)+c_{5}\left(\omega_{\mathrm{OA}_{6}}-\omega_{\mathrm{OA}_{4}}\right)-T_{3}+T_{4}-T_{5}
\end{aligned}
$$




$$
\begin{aligned}
& f_{15}^{\mathrm{H}}=k_{4}\left(\theta_{\mathrm{OA}_{4}}-\theta_{\mathrm{OA}_{5}}\right)+c_{4}\left(\omega_{\mathrm{OA}_{4}}-\omega_{\mathrm{OA}_{5}}\right)-T_{4} \\
& f_{18}^{\mathrm{H}}=k_{5}\left(\theta_{\mathrm{OA}_{4}}-\theta_{\mathrm{OA}_{6}}+\theta_{\mathrm{st}_{6}}\right)+c_{5}\left(\omega_{\mathrm{OA}_{4}}-\omega_{\mathrm{OA}_{6}}\right)+k_{6}\left\{\theta_{\mathrm{OA}_{7}}-\theta_{\mathrm{OA}_{6}}-\left(\theta_{\mathrm{st}_{7}}-\theta_{\mathrm{st}_{6}}\right)\right\}+c_{6}\left(\omega_{\mathrm{OA}_{7}}-\omega_{\mathrm{OA}_{6}}\right)+T_{5}-T_{6} \\
& f_{21}^{\mathrm{H}}=k_{6}\left\{\theta_{\mathrm{OA}_{6}}-\theta_{\mathrm{OA}_{7}}+\left(\theta_{\mathrm{st}_{7}}-\theta_{\mathrm{st}_{6}}\right)\right\}+c_{6}\left(\omega_{\mathrm{OA}_{6}}-\omega_{\mathrm{OA}_{7}}\right)+k_{7}\left\{\theta_{\mathrm{OA}_{8}}-\theta_{\mathrm{OA}_{7}}-\left(\theta_{\mathrm{st}_{8}}-\theta_{\mathrm{st}_{7}}\right)\right\}+c_{7}\left(\omega_{\mathrm{OA}_{8}}-\omega_{\mathrm{OA}_{7}}\right)+T_{6}-T_{7} \\
& f_{24}^{\mathrm{H}}=k_{7}\left\{\theta_{\mathrm{OA}_{7}}-\theta_{\mathrm{OA}_{8}}+\left(\theta_{\mathrm{st}_{8}}-\theta_{\mathrm{st}_{7}}\right)\right\}+c_{7}\left(\omega_{\mathrm{OA}_{7}}-\omega_{\mathrm{OA}_{8}}\right)+T_{7} \\
& f_{27}^{\mathrm{H}}=k_{\theta} \theta_{\mathrm{OA}_{1}}+\mathbf{d}_{X}{ }^{T} \mathbf{p}_{8}^{\prime} F_{P 8_{y}}-\mathbf{d}_{Y}^{T}{ }^{T} \mathbf{p}_{8}^{\prime} F_{P 8_{x}}
\end{aligned}
$$

なお，取っ手と手部との拘束は，図 4 に示すよう取っ手と手部に作用・反作用力 $F_{P 8_{x}}, F_{P 8_{y}}$ を加えることで害 現する. 人間の手部の先端部分 $X Y$ 平面上座標ベクトルを $\mathbf{p}_{8}$ とし, 取っ手の先端部分の $X Y$ 平面上座標ベクトル を $\mathbf{p}_{8}^{\prime}$ とする. また, 座標ベクトル $\mathbf{p}_{8}$ の速度ベクトルを $\mathbf{p}_{8_{v}}$ とし, 座標ベクトル $\mathbf{p}_{8}^{\prime}$ の速度ベクトルを $\mathbf{p}_{8_{v}}{ }^{2}$ とする. この場合，取っ手と手部との間に働くXY平面上の力ベクトル $\mathbf{F}_{\mathrm{P} 8}$ は，次式で表せる.

$$
\mathbf{F}_{\mathbf{P} 8}=k_{8}\left(\mathbf{p}_{\mathbf{8}}-\mathbf{p}_{\mathbf{8}}^{\prime}\right)+c_{8}\left(\mathbf{p}_{8_{\mathrm{v}}}-\mathbf{p}_{\mathbf{8}_{\mathrm{v}}}^{\prime}\right)
$$

取っ手と手部が拘束されていないモデルにおいては，拘束点 $P_{8}$ に設定した粘弾性係数 $\left(k_{8}, c_{8}\right)$ を 0 とする. ここで，式（19）～式 (26）中の $T_{i}$ は各関節の制御トルクであり，式（29）で表せる.ここで, $\mathbf{K}_{\text {human }}(i, n) \quad(i=1,2, \cdots 7, n=1,2, \cdots, 16)$ は, 人間モデルの立位姿勢を保持寸る制御ゲインである.また $\theta_{s t}$ は, 人間モデ ルが立位姿勢の目標とする鉛直方向からの角度である. ここでは $\theta_{s t}=0$ とした. 本研究の数值シミュレーション において, 人間は取っ手を持つだけで意図的な腕の操作はしない状態を想定し, 肩, 肘, 手首に働く制御トルク $T_{i}$ $(i=5,6,7)$ を0 $[\mathrm{Nm}]$ とする.

$$
T_{i}=-\sum_{n=1}^{8} \mathbf{K}_{\text {human }}(i, n)\left(\theta_{\mathrm{OA}_{n}}-\theta_{\mathrm{st}_{n}}\right)-\sum_{n=9}^{16} \mathbf{K}_{\text {human }}(i, n) \omega_{\mathrm{OA}_{n}}
$$

拘束追加前の作用力行列 $\mathbf{f}^{\mathrm{H}}(27 \times 1$ 行列 $)$ は, 各剛体の $\mathrm{XY}$ 方向作用力 $\mathbf{F}_{\mathrm{OA}_{n}}$, 各関節の粘弾性係数 $k_{n}, c_{n}$, 各 剛体の傾き角度 $\theta_{O A_{n}}$ 及び角速度 $\omega_{O A_{n}}$, 各関節に作用寸る回転トルク $T_{i}$ による回転方向作用力 $f_{3 n}^{\mathrm{H}}$ を用いて, 式 (30) で表せる.

$$
\mathbf{f}^{\mathbf{H}}=\left[\begin{array}{c}
\mathbf{F}_{\mathrm{OA}_{1}}^{\prime}-m_{1} \chi \mathbf{V}_{\mathrm{OA}_{1}}^{\prime} \omega_{\mathrm{OA}_{1}} \\
f_{3}^{\mathrm{H}} \\
\vdots \\
\mathbf{F}_{\mathrm{OA}_{8}}^{\prime}-m_{8} \chi \mathbf{V}_{\mathrm{OA}_{8}}^{\prime} \omega_{\mathrm{OA}_{8}} \\
f_{24}^{\mathrm{H}} \\
\mathbf{F}_{\mathrm{OB}_{1}}^{\prime} \\
f_{27}^{\mathrm{H}}
\end{array}\right]
$$

公式より，拘束追加後の質量行列 $\mathbf{m}^{\mathrm{s}} \quad\left(9 \times 9\right.$ 行列） と作用力行列 $\mathbf{f}^{\mathrm{s}} \quad(9 \times 1$ 行列）は次式で表せる.

$$
\begin{aligned}
& \mathbf{m}^{\mathrm{S}}=\mathbf{H}_{\mathrm{S}}^{\mathrm{T}} \mathbf{m}^{\mathrm{H}} \mathbf{H}_{\mathrm{S}} \\
& \mathbf{f}^{\mathrm{S}}=\mathbf{H}_{\mathrm{S}}^{\mathrm{T}}\left\{\mathbf{f}^{\mathrm{H}}-\mathbf{m}^{\mathrm{H}}\left(\frac{d \mathbf{H}_{\mathrm{S}}}{d t} \mathbf{S}\right)\right\}
\end{aligned}
$$

式（6），(31），(32）より，拘束追加後における車両と人間の連成モデルの運動方程式として，式（33）が得られ る. 
$\mathbf{m}^{\mathrm{s}} \dot{\mathbf{S}}=\mathbf{f}^{\mathrm{s}}$

\section{$2 \cdot 5$ 人間の制御系}

人間の制御は最適レギュレータにより設計する. 2.4 節と同様の手順で導出した人間モデルの運動方程式を線形 化し，状態方程式を導出寸る（荒川他，2012a）。制御対象の状態方程式，及び評価関数は次式の通りである.

$$
\begin{aligned}
& \dot{\mathbf{x}}(t)=\mathbf{A}_{1} \mathbf{x}(t)+\mathbf{B}_{1} \mathbf{u}(t), \quad \mathbf{x}(\mathbf{0})=\mathbf{x}_{0} \\
& J(\mathbf{u})=\int_{0}^{\pi}\left(\mathbf{x}(t)^{\mathrm{T}} \mathbf{Q}_{1} \mathbf{x}(t)+\mathbf{u}(t)^{\mathrm{T}} \mathbf{R u}(t)\right) d t, \quad \mathbf{Q}_{1} \geq 0, \quad \mathbf{R}>0
\end{aligned}
$$

ここで, $\mathbf{x}$ は状態変数 $(16 \times 1$ 行列 $), \mathbf{u}$ は制御入力 $(7 \times 1$ 行列 $), \quad \mathbf{A}_{1}(16 \times 16$ 行列 $) \mathbf{B}_{1} \quad(16 \times 7$ 行列 $)$ は状態方程 式を満たす適当な行列である. 式（36）にリッカチ方程式を示す．P はこれを満たす正定対称行列（16×16 行列） である。

$$
\mathbf{A}_{1}^{\mathrm{T}} \mathbf{P}+\mathbf{P A}_{1}-\mathbf{P B}_{1} \mathbf{R}^{-1} \mathbf{B}_{1} \mathbf{P}+\mathbf{Q}_{1}=0
$$

式 (35)，（36）に対して制御の重み $\mathbf{Q}_{1}\left(16 \times 16\right.$ 行列)， R（7×7 行列）を設定することで, 制御ゲイン $\mathbf{K}_{\text {human }}(7 \times 16$ 行列）を導出する.

$$
\mathbf{K}_{\text {human }}=\mathbf{R}^{-1} \mathbf{B}_{1}^{\mathrm{T}} \mathbf{P}
$$

$\mathbf{Q}_{1}, \mathbf{R}$ の值は先行研究（中川他，2013）において，前後方向の動摇運動を模擬できるように設定した.

$$
\begin{aligned}
& \mathbf{Q}_{1}=\operatorname{diag}(50,200,100,300,100,300,300,100,0.01,0.01,0.001,0.01,0.001,0.01,0.01,0.1) \\
& \mathbf{R}=\operatorname{diag}(0.0001,0.001,0.001,0.1,0.0001,0.001,0.01)
\end{aligned}
$$




\section{3. 数值シミュレーション}

本シミュレーションでは，取っ手を持たない場合と持つ場合を考え，車両の加速条件，取っ手を持つ姿勢によ る人間の重心移動を把握する.

\section{$3 \cdot 1$ 取っ手を持たない場合}

\section{$3 \cdot 1 \cdot 1$ シミュレーション条件}

車体に与える水平方向の力を適切に設定することにより, 図 5 に示寸三角波状の加速度で車両を走行させる. 最大加速度と加速時間をパラメータとして, 表 1 に示寸条件でパラメータスタディを行い, 人間の重心移動の違 いを確認した．ただし，三角波については，加速度が最大となる点を基準として，加速波形は左右対称である. また, 人間の重心位置は, 図 6 のように重心を地面に投影した時にできる点 (Center of Gravity Position 以下 COGP) の初期位置からの変位とする. COGP の值は，乗車している人間から見て前方へ重心が移動した場合を正，後方 へ移動した場合を負とする.

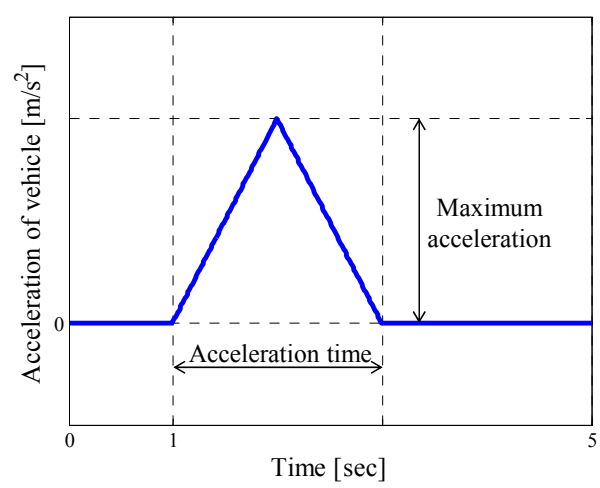

Fig. 5 Condition of vehicle acceleration. The acceleration is a triangular wave form. The maximum acceleration and the acceleration time are variable.

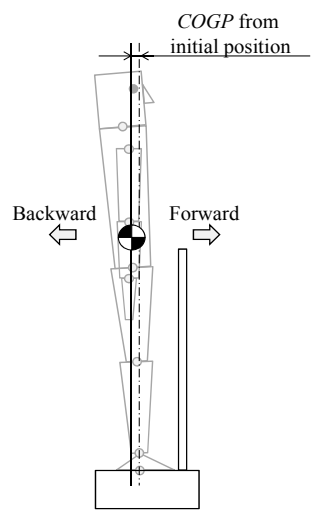

Fig. 6 COGP from initial position. COGP means the center of gravity position of the human. The center of gravity of a human moves backward by the acceleration of the vehicle.

Table 1 Conditions of vehicle

\begin{tabular}{c|c}
\hline Definition & Settings \\
\hline \hline Maximum acceleration & $0.1-4.0\left[\mathrm{~m} / \mathrm{s}^{2}\right]\left(\right.$ Step value $\left.: 0.1\left[\mathrm{~m} / \mathrm{s}^{2}\right]\right)$ \\
\hline Acceleration time & $0.1-2.0[\mathrm{~s}]($ Step value $: 0.1[\mathrm{~s}])$ \\
\hline
\end{tabular}

\section{$3 \cdot 1 \cdot 2$ シミュレーション結果}

加速時間を $1[\mathrm{~s}]$ とし, 最大加速度を変化させた時の重心位置の変化を図 7 に示す. 最大加速度を $1.0\left[\mathrm{~m} / \mathrm{s}^{2}\right]$ とし, 加速時間を変化させた時の重心位置の変化を図 8 に示寸. 図 7 より, 最大加速度が大きくなる程，人間の後方へ の重心移動が大きくなっていることが確認できる．これは，最大加速度が大きくなることにより，人間の各剛体 が受ける慣性力が大きくなるためである. 図 8 より, 加速時間が短い程, 人間の後方への重心移動距離が小さく なる傾向が確認できる. これは，加速時間が短い場合，人間の重心移動が大きくなる前に，加速を終えるためで ある. ただしこれは, 最大加速度に到達する時間が短いということでもあり, 加速度変化が大きくなるため, 加 速開始直後の重心移動は大きくなる.

表 1 のパラメータスタディにより, 車両の最大加速度, 加速時間と人間の重心移動距離の関係を求めた結果を 図 9 に示寸．図9（a）はその関係を三次元で，(b) は等高線で表示したものである. 等高線上の数值は重心移動 距離を意味する．なお，重心移動距離は，車両が加速を開始する $1[\mathrm{~s}]$ での COGP と，COGP の最小值との差とす る. これらの図より, 最大加速度, 加速時間のいずれか, もしくはその両方を小さくすることで, 重心移動を抑 えられることが確認できた。 


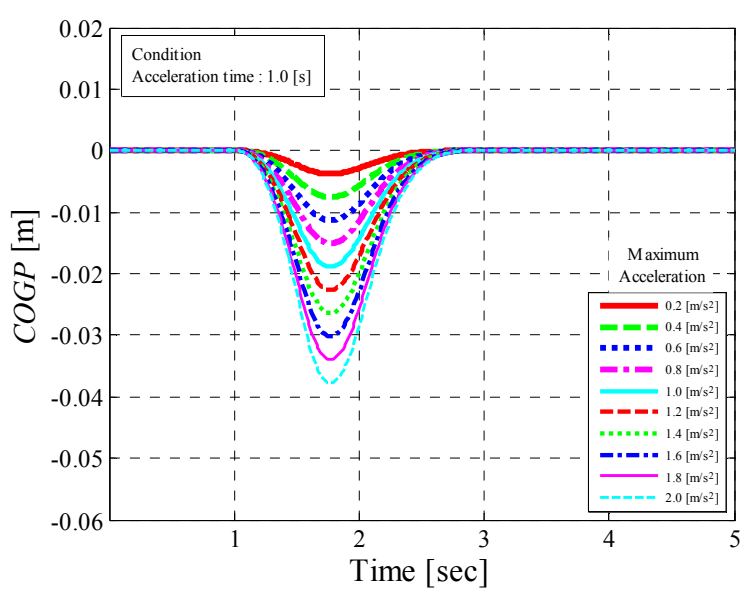

Fig. 7 Change of COGP movement due to the change of maximum acceleration. COGP movement is large when the maximum acceleration is large.

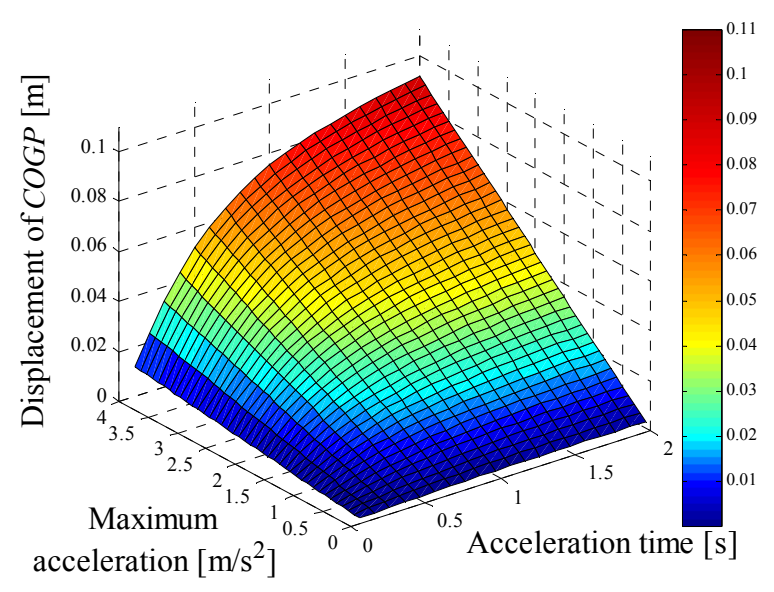

(a) Three-dimensional display

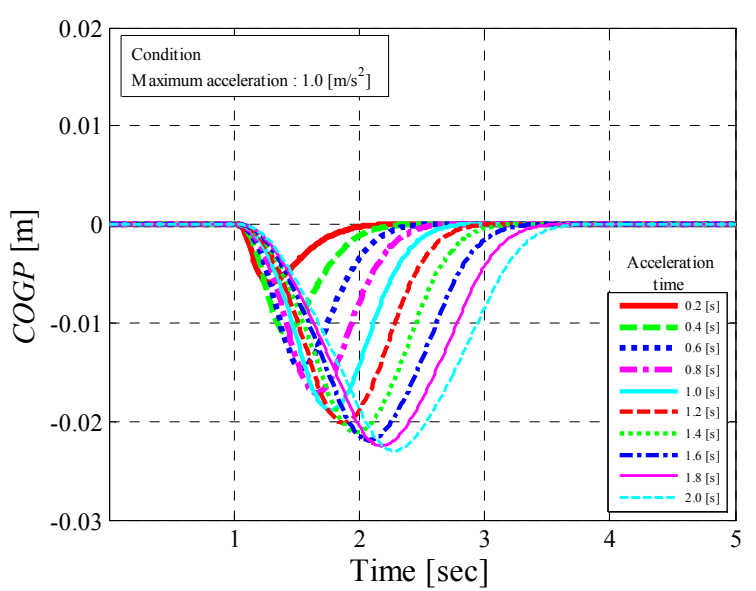

Fig. 8 Change of $C O G P$ movement due to the change of acceleration time. COGP movement is large when the acceleration time is large.

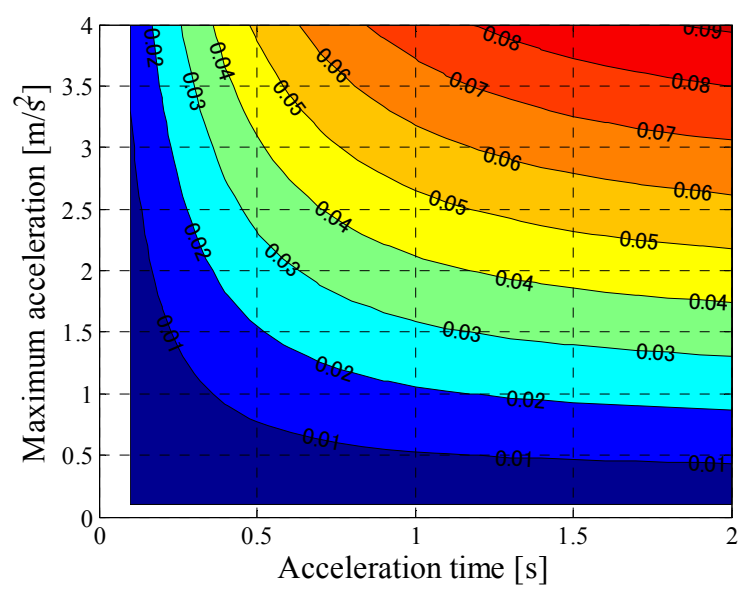

(b) Contour display

Fig. 9 Relation of maximum acceleration, acceleration time and displacement of COGP. (a) is three-dimensional display of the relation, (b) is contour display of the relation. These figures show that the center of gravity movement is smaller when maximum acceleration or acceleration time is small, or both of them are small.

\section{$3 \cdot 1 \cdot 3$ 関連既往研究との比較}

ここでは, 既往研究の研究結果と, 本章 3.1.2 で示した結果を比較することで, 本シミュレーションの妥当性に ついて検証する.

人間の立位姿勢は，その重心位置により安定性が大きく異なることが，既往研究から示唆されている．眓 10 に示すように，足底の踵部を $0 \%$ ，爪先部を 100\%とした場合，重心位置が $35 \%$ 以下のときは，安定した立位姿勢 を取ることができないと言われている（平沢，1960）。また，25\%～65\%の範囲を超えた場合，急激に立位姿勢を 保持することが困難になることがわかっている（藤原他，1982）．以上のことから，加速時間ごとに人間が立位姿 勢を保持できる限界の加速度（以下，限界加速度）を示す線は，およそ足裏の踵部より $25 \%$ お5\%の間にあると 推測される. 本シミュレーションでは，人間の重心位置が $25 \%, 35 \%$ となるのは，それぞれ後方への重心移動距 離が 0.0140 [m], 0.0394 [m] となる時である. そこで, 図(b)の等高線を, 重心位置 $25 \%, 35 \%$ の線で描きかえると， 図 11 となる.グラフ中の折れ線は, 三角波状の加速についての加速時間と限界加速度の関係を実験から導いた結 果を文献（大野，永田，1997）から引用したものである. 
図 11 より, 既往研究の実験から得た限界加速度の折れ線が, 本シミュレーション結果の等高線とおよそ同じ形 状であり, 加速時間が長くなる程，限界加速度が小さいという傾向が一致していることが確認できる. また，実 験結果の折れ線は, シミュレーション結果の等高線における重心位置が $25 \%$ と $35 \%$ となる線の間にあることが確 認でき，前述の立位姿勢の限界についての推測とよく一致している.

以上のことから, 今回のシミュレーション結果から確認できる傾向は, 既往研究の実験で得られた傾向と非常 によく一致しており，本シミュレーションの妥当性を示す結果となった.

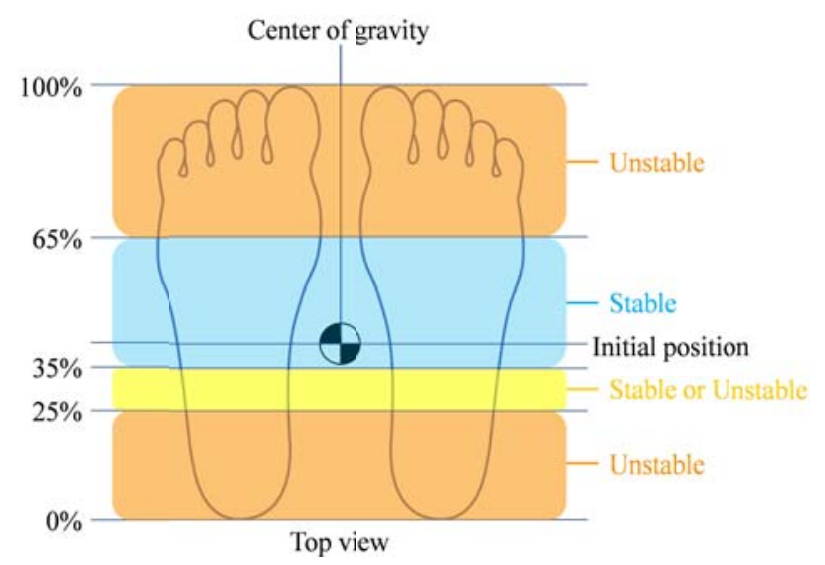

Fig. 10 Stable and unstable area of standing posture. This figure shows the relationship between the center of gravity of the human and the stability of standing posture.

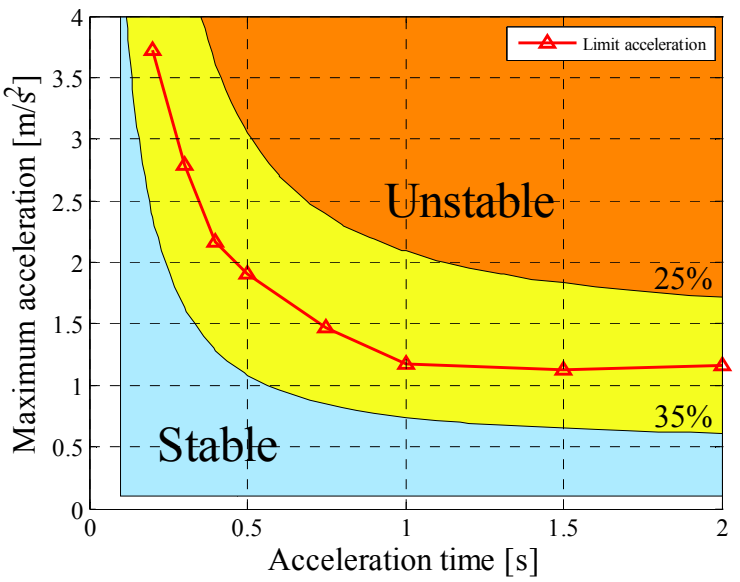

Fig. 11 Evaluation of stability by displacement of COGP. The polygonal line that indicates the limit acceleration obtained by the experiment of the previous study exists between $25 \%$ and $35 \%$ line of COGP.

\section{$3 \cdot 2$ 取っ手を持つ場合}

\section{$3 \cdot 2 \cdot 1$ シミュレーション条件}

最大加速度 $1\left[\mathrm{~m} / \mathrm{s}^{2}\right]$, 加速時間 $1[\mathrm{~s}]$ とした三角波状の加速度で車両を走行させるシミュレーションについて, 表 2 に示寸条件でパラメータスタディを行うことで，上腕部，前腕部の角度と重心移動距離の関係を把握する．た だし，前腕部の目標角度は，関節可動域を考慮し上腕部の目標角度以上の範囲で設定する．また，手部の目標角 度は，前腕部の目標角度と等しい值に設定寸る.

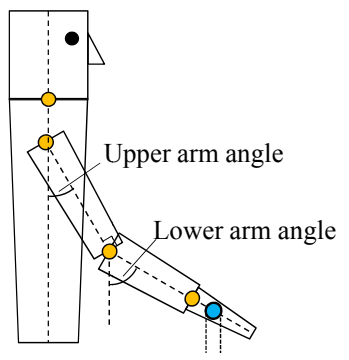

Fig. 12 Explanatory drawing of the upper arm angle and the Table 2 Setting angle of upper arm and lower angle

\begin{tabular}{c|c}
\hline Definition & Settings \\
\hline \hline Upper arm angle & $\begin{array}{c}0-90[\mathrm{deg}] \\
\text { Step value }: 1[\mathrm{deg}]\end{array}$ \\
\hline Lower arm angle & $\begin{array}{c}0-120[\mathrm{deg}] \\
\text { Step value }: 1[\mathrm{deg}]\end{array}$ \\
\hline
\end{tabular}
lower arm angle. The posture of human is determined by providing target angle to the upper arm and the lower arm.

\section{$3 \cdot 2 \cdot 2$ シミュレーション結果}

上腕部，及び前腕部の角度を $10[\mathrm{deg}]$ 刻みとし，重心移動距離を棒グラフで表示した結果を図 13 に示す. 図 13 から，重心移動距離は上腕部，前腕部の角度の組み合わせにより大きく異なることが分かる．上腕部の角度が大 
きいほど，重心移動距離が小さいこと，また重心移動距離が小さくなる前腕部の角度は，上腕部の角度により異 なることが確認できる．特に，上腕部と前腕部が同じ角度で，かつその角度が 30 [ deg] 以上となるような姿勢の 場合, 取っ手による重心移動の抑制効果が高いことが確認できる．ただし，車両上のスペースを考慮すると上腕 部の角度は 30〜60 [deg]程度が妥当であると考えられる.

重心移動が抑制される理由は, 取っ手を持つことにより, 各剛体の可動範囲が制限されることや, 腕部の粘弾 性により, 重心位置の後方への変位が抑制されること等が考えられる.ただし, 腕部の角度によって, 重心移動 に影響を与える支配的な要素は異なると考えられる．このことを詳しく考察する為，上腕部・前腕部角度と加速 開始以降に肩・肘・手首に生じたトルクの平均值との関係を求めたところ, 図 14〜図 16 に示寸結果となった. トルクについては反時計回りを正とする. なお，グラフ中の曲面を見易くするため, 図 14 のみ, 腕部角度に関す る軸の表記が異なる. 図 14, 図 15 より, 肩のトルクは負, 肘のトルクは概ね正の值となっていることが確認で きる.これは, 図 17(a)に示すよう, 車両が加速する際, 重心移動を抑制する方向に, 肩・肘に粘弾性によるトル クが生じていることを表している. 図 16 より，手首のトルクは，上腕部・前腕部の角度に関わらず，およそ 0 となっている．この理由として，手首の目標角度を前腕部と同じ值に設定したことが考えられる.

続いて, 肩・肘に生じるトルクの傾向について検討寸る. 図 14, 図 15 から, 上腕部・前腕部の角度により, 加速時に生じる肩・肘のトルクの大きさが変化していることが確認できる. 上腕部の角度に着目すると, 上腕部 の角度が小さくなる程, トルクの絶対值が大きくなっていることがわかる. この理由として, 上腕部は, 図 17(b) に示すように，その目標角度が小さい程回転し易いため, 肩・肘に生じる粘弾性によるトルクも大きくなること が考えられる，逆に，上腕部の角度が大きい場合，肩・肘に生じるトルクの絶対值が小さくなっているが，これ は, 胴体部に対して上腕部がほとんど回転していないためである. 即ち, 図 17(c)のように可動範囲が制限されて いると考えられる. 次に, 前腕部の角度に着目する. 肩・肘に生じるトルクは, 前腕部が上腕部と同じ角度にな る場合に最も小さく, また, 前腕部の角度が増加するにつれて, 大きくなることが確認できる. この理由として, 前腕部と上腕部が同じ角度である場合, 図 17(d)のように胴体部の可動範囲が著しく制限されていることが考えら れる. 前腕部の角度が増加すると, 図 17(e)のようにそれに応じて上腕部, 胴体部の動きが大きくなり, トルクが 大きくなると考えられる.

上記のように，人間の重心移動には，取っ手を持つ姿勢による各剛体の可動範囲の違いと，肩・肘に生じる卜 ルクが影響していると考えられる，ただし，重心移動を抑制するメカニズムは腕部の姿勢により異なると考えら れる. 上腕部の角度が小さい場合, 上腕部・胴体部の可動範囲はほとんど制限されない. そのため, 重心移動を 抑制する主たる要因は腕部の粘弾性のトルクであると考えられる. 上腕部の角度が大きい場合, 肩・肘に生じる トルクは小さいにも関わらず，重心移動は大幅に抑制されている．このことから，上腕部・胴体部の可動範囲が 制限されていることが主たる要因となり, 重心移動が抑制されていると考えられる. 前腕部の角度については, その角度が大きくなる程, 肩・肘に生じるトルクの絶対值が大きくなることが明らかとなったが, 重心移動距離 が最小となる前腕部の角度は，上腕部の角度によって異なることがわかった．この理由として，上腕部が，肩・ 肘に生じたトルクの両方の影響を受けていることや, 前腕部の角度により上腕部の可動範囲が変化することが考 えられる。

\section{4. 結 言}

立ち乗り式四輪型車両に乗車した人間の重心移動を検討する為, マルチボディダイナミクスの拘束条件追加法 を用いて，取っ手を持たない場合と持つ場合のモデルを構築した．車両が三角波状の加速度で走行する場合につ いて, 加速条件（最大加速度, 加速時間）や取っ手を持つ姿勢を変えた時の重心移動の違いについて検討した. 解析の結果, 最大加速度, 加速時間のいずれか, もしくはその両方を小さくすることで, 重心移動が小さくなる ことを明らかにした. 取っ手を持つ場合, 上腕部の角度が大きい程, 重心移動距離が小さくなることが分かった. 上腕部と前腕部が同じ角度で，かつその角度が 30 [deg]以上となる場合，取っ手による重心移動の抑制効果が高 いと考えられる．また，車両上のスペースを考慮すると上腕部の角度は 30～60 [deg]程度が妥当であると考えら れる. 


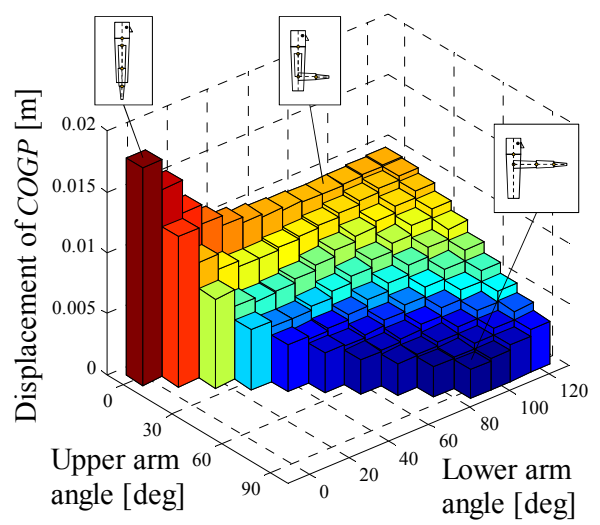

Fig. 13 Relation of the upper arm angle, the lower arm angle and the displacement of COGP. This figure shows that as the angle of the upper arm is large, the motion of the center of gravity is decreased.

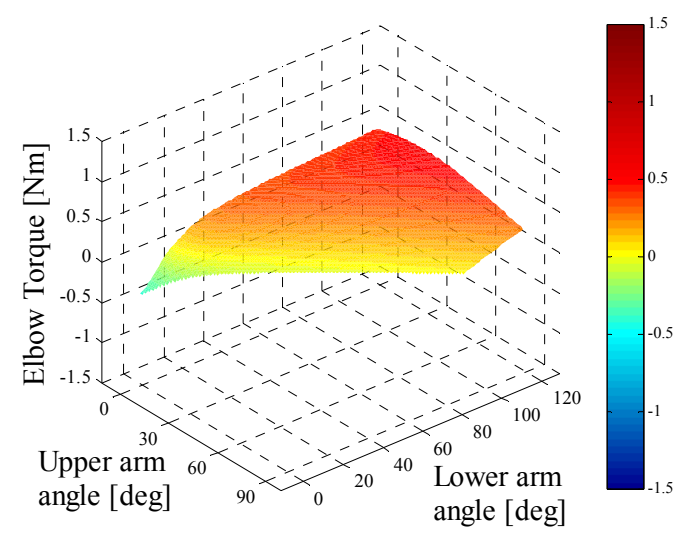

Fig. 15 Elbow torque of a human. The absolute value of elbow torque increases when the upper arm angle is small.

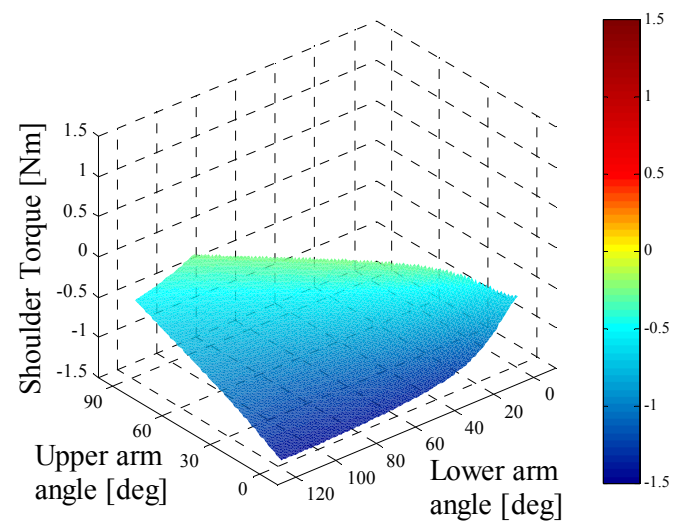

Fig. 14 Shoulder torque of a human. The absolute value of shoulder torque increases when the upper arm angle is small.

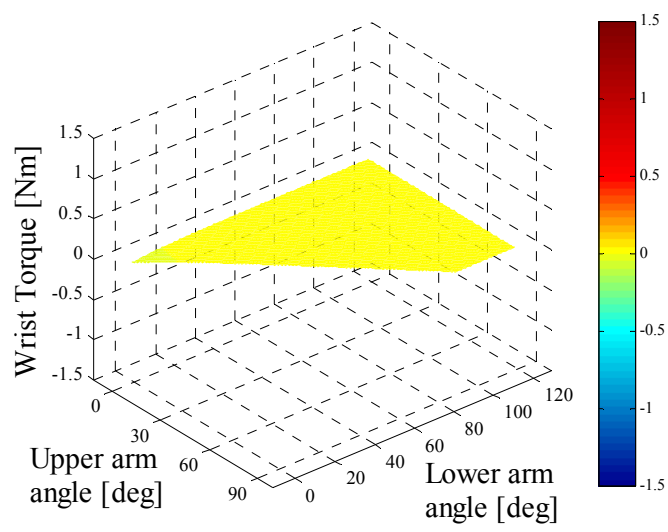

Fig. 16 Wrist torque of a human. Because the target angle of the lower arm and the hand is the same value, the absolute value of wrist is almost zero.

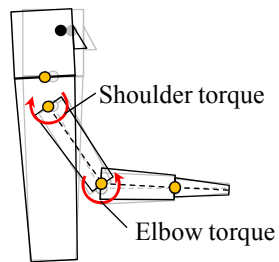

(a) Torque of shoulder and elbow

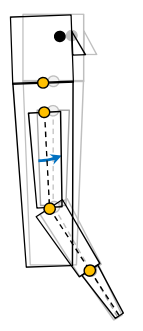

(b) Upper arm angle : Small

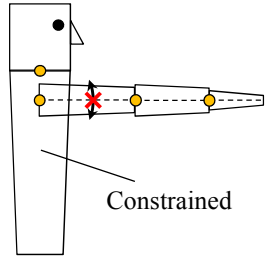

(c) Upper arm angle :large

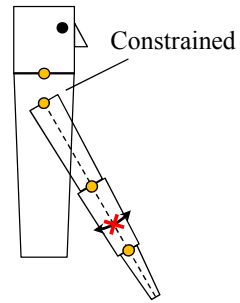

(d) Upper arm angle $=$ Lower arm angle

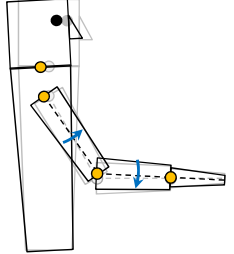

(e) Lower arm angle : large

Fig. 17 Explanatory drawing of a human movement. (a) shows the direction of shoulder and elbow torque. (b) shows that the upper arm is easy to rotate when the upper arm angle is small. The body of human is constrained when the upper arm angle is large as shown in (c), and the upper arm is constrained when the upper arm angle and the lower arm angle are the same value. (e) shows that the upper arm and the body are easy to move when the lower arm angle is small.

\section{謝 辞}

本研究は，科学研究費補助金 24760188 の助成を受けたものである。ここに感謝の意を表する. 


\section{文献}

荒川俊介，中川智皓，新谷篤彦，伊藤智博，マルチボディダイナミクスを用いた倒立振子型車両と操縦者の挙動 に関する基礎検討，日本機械学会論文集 C 編，Vol.78，No.789 (2012a)，pp.1497-1506.

荒川俊介, 中川智皓, 新谷篤彦, 伊藤智博, マルチボディダイナミクスを用いた倒立振子型車両と操縦者の運動 解析，Dynamics and Design Conference 2012 CD-ROM 論文集 講演番号 840 (2012b).

藤原勝夫, 池上晴夫, 岡田守彦, 小山吉明, 立位姿勢の安定性における年齢および下肢筋力の関与, 人類誌 (1982), pp.385-400.

平沢弥一郎，新しい人体論，日本放送出版会 (1960), pp.213-217.

本田技研工業株式会社，本田技研工業株式会社 HP，<http://www.honda.co.jp/UNI-CUB/>，（参照日 2016 年 2 月 6 日）。

中川智皓，今村和樹，新谷篤彦，伊藤智博，パーソナルモビリティ・ビークルの大きさと歩行者の親和性に関す る実験的研究，日本機械学会論文集 C 編，Vol.78，No.794 (2012)，pp.3332-3342.

中川智皓, 荒川俊介, 新谷篤彦, 伊藤智博, マルチボディダイナミクスを用いた加減速操作時における倒立振子 型車両と操縦者の運動解析, Dynamics and Design Conference 2013 USB 論文集 講演番号 406 (2013).

大野央人，永田久雄，加速刺激に対する立位姿勢の安定性に関する研究 その 6 : 加速刺激の波形の相違が姿勢反 応におよぼす影響，人間工学特別号，Vol. 33 (1997) pp.400-401.

セグウェイジャパン株式会社, Segway Inc.Top page, <http://www.segway-japan.net/lineup/index.html>, (参照日 2016 年 2 月 6 日）。

田島洋, マルチボディダイナミクスの基礎３次元運動方程式の立て方，東京電機大学出版局 (2006).

トヨタ自動車，トヨタ自動車 HP，<http:/www.toyota.co.jp/jpn/tech/personal_mobility/winglet.html>，参照日 2016 年 2 月 6 日）。

\section{References}

Arakawa, S., Nakagawa, C., Shintani, A. and Ito, T., Basic study on the behavior of inverted pendulum vehicle and driver using multibody dynamics, Transactions of the JSME (in Japanese), Series C, Vol.78, No.789 (2012a), pp.1497-1506.

Arakawa, S., Nakagawa, C., Shintani, A. and Ito, T., Dynamic analysis of inverted pendulum vehicle and driver using multibody dynamics, Proceedings of Dynamics and Design Conference, No.840 (2012b) (in Japanese).

Fujiwara, M., Ikegami, H., Okada, M. and Koyama, Y., Contribution of Age and Muscle Strength of Lower Limbs to Steadiness and Stability in Standing Posture, Journal of the Anthropological Society of Nippon (1982), pp.385-400 (in Japanese).

Hirasawa, Y., A new theory of human, NHK Publishing Co., Ltd. (1960), pp.213-217 (in Japanese).

Honda Motor Co., Ltd, available from <http:/www.honda.co.jp/UNI-CUB/>, (accessed on 6 February, 2016).

Nakagawa, C., Imamura, K., Shintani, A. and Ito, T., Experimental Study on the Influence of the Size of Personal Mobility Vehicle on Pedestrians, Transactions of the Japan Society of Mechanical Engineers, Series C, Vol.78, No.794 (2012), pp.3332-3342 (in Japanese).

Nakagawa, C., Arakawa, S., Shintani, A. and Ito, T., Dynamic analysis of inverted pendulum vehicle and driver during acceleration and deceleration using multibody dynamics, Proceedings of Dynamics and Design Conference, No.406 (2013) (in Japanese).

Ohno, H. and Nagata, H., Studies on stability of human standing posture against accelerations. Part 6 Postural instability under sine-, rectangular or triangular- shaped acceleration, The Japanese Journal of Ergonomics Vol.33 (1997), pp.400-401 (in Japanese).

Segway Inc., Segway Inc. Top page, available from <http:/www.segway-japan.net/lineup/index.html>, (accessed on 6 February, 2016).

Tajima, H., Fundamentals of multibody dynamics, Tokyo Denki University Press (2006), (in Japanese).

TOYOTA Motor Corporation, available from <http://www.toyota.co.jp/jpn/tech/personal_mobility/winglet.html>, (accessed on 6 February, 2016). 